\title{
ERRATUM
}

\section{Reversal of Transjugular Intrahepatic Portosystemic Shunt (TIPS)-Induced Hepatic Encephalopathy Using a Strictured Self-Expanding Covered Stent}

\author{
Mitchell W. Cox, Peter H. Lin, Ruth L. Bush, Alan B. Lumsden \\ Division of Vascular Surgery \& Endovascular Therapy, Michael E. DeBakey Department of Surgery, Baylor College of Medicine, Houston, Texas, USA
}

RE: Cardiovasc Intervent Radiol 26:539-542 (2003). Dr. George D. Soltes was listed in error as a co-author of this article. The authors are as follows: Mitchell W. Cox, Peter H. Lin, Ruth L. Bush, and Alan B. Lumsden, and are shown correctly above. 